\title{
Glycemic Control in Inpatients With Diabetes Following August Changeover of Trainee Doctors in England
}

\author{
Rajesh Rajendran, AHEA, MRCP(UK $)^{1}$, Dina Jankovic, MPharm, MSc², Gerry Rayman, MD, FRCP ${ }^{1 *}$
}

${ }^{1}$ Diabetes Centre, The Ipswich Hospital NHS Trust, Ipswich, United Kingdom; ${ }^{2}$ Centre of Health Economics, University of York, York, United Kingdom.

The first Wednesday of August is the day of changeover of trainee doctors in England. It is widely perceived that inexperience and nonfamiliarity with the new hospital systems and policies in these first few weeks lead to increased medical errors, mismanagement, and mortality. The aim of this study was to analyze the impact of the August changeover of trainee doctors on inpatient glycemic control in a single English hospital. This is currently unknown in England. Overall, 16,870 patient-day capillary glucose reading measures in 2730 inpatients with diabetes were analyzed for 4 weeks before and after the changeover period for the years 2012, 2013, and 2014. Only inpatients hospitalized for longer than 1 day were included. Contrary to expectations, inpatient glycemic control did not worsen in the first 4 weeks after changeover compared to the preceding 4 weeks before changeover in the 3-year period. This may be due to forethought and planning by the deanery foundation school and the inpatient diabetes team in this hospital. Journal of Hospital Medicine 2016;11:206-209. (C) 2015 Society of Hospital Medicine
In England, the day when trainee doctors start work for the first time in their careers or rotate to a different hospital is the first Wednesday of August. This is often referred to as the "Black Wednesday" in the National Health Service (NHS), as it is widely perceived that inexperience and nonfamiliarity with the new hospital systems and policies in these first few weeks lead to increased medical errors and mismanagement and may therefore cost lives. ${ }^{1}$ However, there is very little evidence in favor of this widely held view in the NHS. A 2009 English study found a small but significant increase of $6 \%$ in the odds of death for inpatients admitted in the week following the first Wednesday in August than in the week following the last Wednesday in July, whereas a previous report did not support this. ${ }^{2,3}$ In the United States, the resident trainee doctor's changeover occurs in July, and its negative impact on patient outcomes is often dubbed the "July phenomenon." ${ }^{4}$ With conflicting reports of the July phenomenon on patient outcomes, ${ }^{5-7}$ Young et al. systematically reviewed 39 studies and concluded that the July phenomenon exists in that there is increased mortality around the changeover period. ${ }^{4}$

It can be hypothesized that glycemic control in inpatients with diabetes would be worse in the immediate period following changeover of trainee doctors for the

*Address for correspondence and reprint requests: Gerry Rayman, MD, Consultant Physician and Lead for the National Inpatient Diabetes Audit, Diabetes Centre, The Ipswich Hospital NHS Trust, Heath Road, Ipswich, IP4 5PD, United Kingdom; Telephone: 0044-1473704183; Fax: 0044-1473704197; E-mail: gerry.rayman@ipswichhospital.nhs.uk

Additional Supporting Information may be found in the online version of this article.

Received: March 8, 2015; Revised: September 14, 2015; Accepted: September 16, 2015

2015 Society of Hospital Medicine DOI 10.1002/jhm.2496

Published online in Wiley Online Library (Wileyonlinelibrary.com). same reasons mentioned earlier that impact mortality. However, contrary to expectations, a recent singlehospital study from the United States reported that changeover of resident trainee doctors did not worsen inpatient glycemic control. ${ }^{8}$ Although the lack of confidence among trainee doctors in inpatient diabetes management has been clearly demonstrated in England, ${ }^{9}$ the impact of August changeover of trainee doctors on inpatient glycemic control is unknown. The aim of this study was to determine whether the August changeover of trainee doctors impacted on glycemic control in inpatients with diabetes in a single English hospital.

\section{MATERIAL AND METHODS}

The study setting was a medium-sized 550-bed hospital in England that serves a population of approximately 360,000 residents. Capillary blood glucose (CBG) readings for adult inpatients across all wards were downloaded from the Precision Web Point-of-Care Data Management System (Abbott Diabetes Care Inc., Alameda, CA), an electronic database where all the CBG readings for inpatients are stored. Patient administration data were used to identify those with diabetes admitted to the hospital for at least 1 day, and only their CBG readings were included in this study. Glucometrics, a term coined by Goldberg et al., refers to standardized glucose performance metrics to assess the quality of inpatient glycemic control. ${ }^{10}$ In this study, patient-day glucometric measures were used, as they are considered the best indicator of inpatient glycemic control compared to other glucometrics. ${ }^{10}$ Patient-day glucometrics were analyzed for 4 weeks before and after Black Wednesday for the years 2012, 2013, and 2014 using Microsoft Excel 2007 (Microsoft Corp., Redmond, WA) and R version 3.1.0 (The R Foundation, Vienna, Austria). Patient-day glucometrics analyzed were hypoglycemia (any CBG $\leq 2.2 \mathrm{mmol} / \mathrm{L}$ 
TABLE 1. Effect of Three Covariates on Blood Glucose Levels

\begin{tabular}{|c|c|c|c|c|c|c|}
\hline \multirow[b]{2}{*}{ Covariate } & \multicolumn{6}{|c|}{ Outcome } \\
\hline & $\begin{array}{l}\text { Change in Mean } \\
\text { CBG for Each } \\
\text { Patient-Day, } \\
\mathrm{mmol} / \mathrm{L} \text { (mg/dL) }\end{array}$ & $\begin{array}{c}\text { Change in \% of } \\
\text { Patient-Days With } \\
\text { Any CBG } \leq 2.2 \mathrm{mmol} / \mathrm{L} \\
(40 \mathrm{mg} / \mathrm{dL})\end{array}$ & $\begin{array}{c}\text { Change in \% of } \\
\text { Patient-Days With } \\
\text { Any CBG } \leq 2.9 \mathrm{mmol} / \mathrm{L} \\
(52 \mathrm{mg} / \mathrm{dL})\end{array}$ & $\begin{array}{c}\text { Change in } \% \text { of } \\
\text { Patient-Days With } \\
\text { Any CBG } \leq 3.9 \mathrm{mmol} / \mathrm{L} \\
(72 \mathrm{mg} / \mathrm{dL})\end{array}$ & $\begin{array}{c}\text { Change in \% of } \\
\text { Patient-Days With } \\
\text { Mean CBG Between } \\
4 \text { and } 12 \mathrm{mmol} / \mathrm{L} \\
(73-216 \mathrm{mg} / \mathrm{dL})\end{array}$ & $\begin{array}{c}\text { Change in \% of } \\
\text { Patient-Days With } \\
\text { Any CBG }>12 \mathrm{mmol} / \mathrm{L} \\
(218 \mathrm{mg} / \mathrm{dL})\end{array}$ \\
\hline $\begin{array}{c}\text { Additional day in } \\
\text { the hospital }\end{array}$ & $0.015(0.27), P<0.001^{*}$ & $1.00, P=0.605$ & $1.00, P=0.986$ & $1.005, P=0.004 \uparrow$ & $0.99, P<0.001^{*}$ & $1.01, P<0.001^{*}$ \\
\hline Ward (range) & $\begin{array}{c}0.59-13.68 \\
(10.62-246.24)\end{array}$ & $0.37-22.71$ & $0-3.62$ & $0-3.10$ & $0-47,124.14$ & $0-4,094,900$ \\
\hline$R^{2} /$ pseudo- $R_{\text {McFadden }}^{2}$ & 0.0247 & 0.0503 & 0.0363 & 0.0270 & 0.0140 & 0.0243 \\
\hline
\end{tabular}

Each column presents results for 1 outcome (model). Coefficients for mean patient-day glucose (model 1) represent the unit change in mean patient-day glucose associated with the corresponding covariate. Negative values indicate a reduction in mean patient-day CBG, and vice versa. The remaining 5 outcomes indicate the factor change in relative risk, in this case proportion of patient-days, associated with the corresponding covariate. Values between 0 and 1 indicate a reduction in relative risk, whereas values greater than 1 indicate increased relative risk. Additional days in the hospital are the effect of each additional day of hospitalization on outcomes. For example, in patients who stay in the hospital for a total of 5 days, the proportion of patient-days with at least 1 reading over $12 \mathrm{mmol} / \mathrm{L}(218 \mathrm{mg} / \mathrm{dL})$ is $1.04\left(1.01^{4}\right)$ times the proportion of patients who stay in the hospital for 1 day only. Similarly, additional patients monitored indicate the effect of monitoring each additional patient in the hospital on the day the patient-day reading was calculated. "Ward" represents the effect of staying on a particular ward. There were 31 wards in total where at least 1 patient was monitored during the study. Figures represent the range-minimum and maximum change-in outcome associated with any ward, in comparison to the baseline ward, which was chosen at random and kept constant for all 6 models. Goodness of fit for the first linear model was estimated using $R^{2}$. Goodness of fit for the remaining 5 logistic models was calculated using $R^{2}$ McFadden. See text for interpretation. Abbreviations: CBG, capillary blood glucose. *Very highly significant. †Highly significant. †̦Significant.

$[40 \mathrm{mg} / \mathrm{dL}]$, any $\mathrm{CBG} \leq 2.9 \mathrm{mmol} / \mathrm{L}[52 \mathrm{mg} / \mathrm{dL}]$, any $\mathrm{CBG} \leq 3.9 \mathrm{mmol} / \mathrm{L}[72 \mathrm{mg} / \mathrm{dL}]$ ), normoglycemia (mean CBGs between 4 and $12 \mathrm{mmol} / \mathrm{L}$ [73-216 mg/dL]), hyperglycemia (any CBG $\geq 12.1 \mathrm{mmol} / \mathrm{L}[218 \mathrm{mg} / \mathrm{dL}]$ ), and mean CBG. Proportions were compared using the $z$ test, whereas sample means between the groups were compared by nonparametric Mann-Whitney $U$ tests, as per statistical literature. ${ }^{11}$ All $P$ values are 2 -tailed, and $<0.05$ was considered statistically significant.

Patient characteristics and healthcare professional's workload were identified as potential causes of variation in CBG readings. Regression analysis of covariance was used to identify and adjust for these factors when comparing mean glucose readings. Binomial logistic regression was used to adjust proportions of patients-days with readings out of range and patientdays with mean readings within range. Variables tested were length of stay as a proxy for severity of condition, number of patients whose CBG were measured in the hospital in a day as a proxy for the healthcare professional's workload, and location of the patient to account for variation in patient characteristics as the wards were specialty based. Goodness of fit was tested using the $R^{2}$ value in the linear model, which indicates the proportion of outcome that is explained by the model. For binomial models, McFadden's pseudo $R^{2}$ (pseudo- $R^{2}$ McFadden) was used as advised for logistic models. McFadden's pseudo- $R^{2}$ ranges from 0 to 1 , but unlike $R^{2}$ in ordinary linear regression, values tend to be significantly lower: McFadden's pseudo $R^{2}$ values between 0.2 and 0.4 indicate excellent fit. ${ }^{12}$

\section{RESULTS}

A total of 16,870 patient-day CBG measures in 2730 inpatients with diabetes were analyzed. The results of all regressions are presented in Table 1 . The coefficients in the first model represent the effect of each covariate on mean patient-day CBG. For example, each extra day of hospitalization was associated with a $0.02 \mathrm{mmol} / \mathrm{L}(0.36 \mathrm{mg} / \mathrm{dL})$ increase in mean patientday reading, ceteris paribus. The remaining models indicate the change in relative risk (in this case the proportion of patient-days) associated with the covariates. For example, in patients who were hospitalized for 3 days, the proportion of patient-days with at least $1 \mathrm{CBG}$ greater than $12 \mathrm{mmol} / \mathrm{L}(216 \mathrm{mg} / \mathrm{dL})$ was 1.01 times the comparable proportion of patients who were hospitalized for 2 days. Each additional day in the hospital significantly increased the mean CBG by $0.015 \mathrm{mmol} / \mathrm{L}(0.27 \mathrm{mg} / \mathrm{dL})$ and increased the risk of having at least 1 reading below $3.9 \mathrm{mmol} / \mathrm{L}(72 \mathrm{mg} /$ $\mathrm{dL}$ ) or above $12 \mathrm{mmol} / \mathrm{L}(216 \mathrm{mg} / \mathrm{dL})$. Monitoring more patients in a day also affected outcomes, although the effect was small. Each additional patient monitored reduced mean patient-day CBG by 0.011 $\mathrm{mmol} / \mathrm{L}(0.198 \mathrm{mg} / \mathrm{dL})$ and increased the proportion of patients with at least 1 reading below $4 \mathrm{mmol} / \mathrm{L}$ $(72 \mathrm{mg} / \mathrm{dL}) 1.01$ times. Location of the patient also significantly affected CBG readings. This could have been due to either ward or patient characteristics, but lack of data on each ward's healthcare personnel and individual patient characteristics prevented further analysis of this effect, and therefore the results were used for adjustment only. All models have relatively low predictive power, as demonstrated by the low $R^{2}$ and pseudo- $R^{2}$ McFadden values. In the linear model that estimated the effect of covariates on mean patient-day CBG, the $R^{2}$ is 0.0270 , indicating that only $2.70 \%$ of results were explained by the covariates in the model. The pseudo- $R^{2}$ McFadden varied between 0.0146 and 0.0540 , as presented in Table 1 . Although the pseudo- 
TABLE 2. Adjusted Patient-Day Glucometric Data for Four Weeks Before and After the August Changeover for the Years 2012, 2013, and 2014

\begin{tabular}{|c|c|c|c|c|c|c|}
\hline & \multicolumn{2}{|c|}{2012} & \multicolumn{2}{|r|}{2013} & \multicolumn{2}{|r|}{2014} \\
\hline & $\begin{array}{c}\text { Before } \\
\text { Changeover }\end{array}$ & $\begin{array}{c}\text { After } \\
\text { Changeover }\end{array}$ & $\begin{array}{c}\text { Before } \\
\text { Changeover }\end{array}$ & $\begin{array}{c}\text { After } \\
\text { Changeover }\end{array}$ & $\begin{array}{c}\text { Before } \\
\text { Changeover }\end{array}$ & $\begin{array}{c}\text { After } \\
\text { Changeover }\end{array}$ \\
\hline No. of inpatients with diabetes whose CBG readings were analyzed & 470 & 482 & 464 & 427 & 440 & 447 \\
\hline No. of patient-day CBG readings analyzed & 2917 & 3159 & 3097 & 2588 & 2484 & 2625 \\
\hline Mean no. of CBG readings per patient-day (range) & $2.5(1-27)$ & $2.5(1-23), P=0.676$ & $2.6(1-21)$ & $2.4(1-18), P=0.009^{*}$ & $2.5(1-20)$ & $2.4(1-20), P=0.028 \dagger$ \\
\hline $\begin{array}{l}\text { Mean no. of CBG readings per patient-day (range) in those where at least } \\
1 \text { reading was CBG } \leq 3.9 \mathrm{mmol} / \mathrm{L}(72 \mathrm{mg} / \mathrm{dL} \text { ) or CBG } \\
\geq 12.1 \mathrm{mmo} / \mathrm{L}(218 \mathrm{mg} / \mathrm{dL})\end{array}$ & $3.8(1-27)$ & $3.8(1-23)$ & $3.7(1-21)$ & $3.5(1-18)$ & $3.2(1-20)$ & $3.5(1-20)$ \\
\hline $\begin{array}{l}\text { Mean no. of CBG readings per patient-day (range) in those where } \\
\text { all CBG readings were between } 4 \text { and } 12 \mathrm{mmol} / \mathrm{L}(73-216 \mathrm{mg} / \mathrm{dL})\end{array}$ & $1.8(1-27)$ & $1.8(1-12)$ & $1.8(1-12)$ & $1.8(1-17)$ & $1.7(1-11)$ & $1.7(1-15)$ \\
\hline$\%$ of patient-days with any $\mathrm{CBG} \leq 2.2 \mathrm{mmo} / \mathrm{L}(40 \mathrm{mg} / \mathrm{dL})$ & $0.99 \%$ & $1.09 \%, P=0.703$ & $1.03 \%$ & $0.88 \%, P=0.544$ & $0.84 \%$ & $0.87 \%, P=0.927$ \\
\hline$\%$ of patient-days with any $\mathrm{CBG} \leq 2.9 \mathrm{mmol} / \mathrm{L}(52 \mathrm{mg} / \mathrm{dL})$ & $2.53 \%$ & $2.68 \%, P=0.708$ & $2.63 \%$ & $1.35 \%, P=0.490$ & $2.24 \%$ & $2.31 \%, P=0.874$ \\
\hline$\%$ of patient-days with any $\mathrm{CBG} \leq 3.9 \mathrm{mmol} / \mathrm{L}(72 \mathrm{mg} / \mathrm{dL})$ & $7.25 \%$ & $7.42 \%, P=0.792$ & $7.56 \%$ & $6.93 \%, P=0.361$ & $6.55 \%$ & $6.70 \%, P=0.858$ \\
\hline $\begin{array}{l}\text { \% of patient-days with mean CBG between } 4 \text { and } 12 \text { mmol/L } \\
\text { (73-216 mg/dL) }\end{array}$ & $79.10 \%$ & $79.89 \%, P=0.446$ & $78.69 \%$ & $78.58 \%, P=0.924$ & $78.65 \%$ & $78.61 \%, P=0.973$ \\
\hline \% of patient-days with any CBG $\geq 12.1 \mathrm{mmo} / \mathrm{L}$ (218 mg/dL) & $32.32 \%$ & $31.40 \%, P=0.443$ & $32.29 \%$ & $32.88 \%, P=0.634$ & $32.78 \%$ & $32.66 \%, P=0.928$ \\
\hline Median of mean CBG for each patient-day in mmo/L (mg/dL) & $8.0(144.6)$ & $7.8(140.0)$ & $8.4(151.5)$ & $8.3(150.2)$ & $8.9(159.8)$ & $8.8(157.8)$ \\
\hline Mean of mean CBG for each patient-day in mmol/L (standard deviation) & $9.1(4.0)$ & $8.8(4.1), P=0.033+$ & $9.4(4.1)$ & $9.2(4.0), P=0.075$ & $9.8(4.1)$ & $9.6(3.8), P=0.189$ \\
\hline
\end{tabular}

NOTE: Abbreviations: CBG, capillary blood glucose. *Highly significant. †Significant.

$R^{2}$ McFadden generally had lower values than the $R^{2}$ for the linear models, values of 0.0540 and below are considered to be relatively low. ${ }^{12}$

Table 2 summarizes outcomes for the 3 years individually. The results suggest that all indices of inpatient glycemic control that were analyzedhypoglycemia, normoglycemia, hyperglycemia, and mean CBG-did not worsen in August compared to July that year. The results are presented after adjustment for variation in the length of stay, number of patients monitored in a day, and location of the patient. Their effect on the difference in proportions of patients with at least 1 reading out of range and mean reading within range were not statistically significant. However, their effect on mean patient-day CBG measures was statistically significant, although the effect was only a small decrease $(0.4 \mathrm{mmol} / \mathrm{L}$ or $7.2 \mathrm{mg} / \mathrm{dL}$ ) in the mean CBG (see Supporting Table 1 in the online version of this article for unadjusted readings).

\section{DISCUSSION}

This study shows that contrary to expectation, inpatient glycemic control did not worsen in the 4 weeks following the August changeover of trainee doctors for the years 2012, 2013, and 2014. In fact, inpatient glycemic control was marginally better in the first 4 weeks after changeover each year compared to the preceding 4 weeks before changeover. There may be several reasons for the findings in this study. First, since 2010 in this hospital and since 2012 nationally (further to direction from NHS England Medical Director Sir Bruce Keogh), it has become established practice that newly qualified trainee doctors shadow their colleagues at work a week prior to Black
Wednesday. ${ }^{13,14}$ The purpose of this practice, called the "preparation for professional practice" is to familiarize trainee doctors with the hospital protocols and systems, improve their confidence, and potentially reduce medical errors when starting work. Second, since 2012, this hospital has also implemented the Joint British Diabetes Societies' national guidelines in managing inpatients with diabetes. ${ }^{15}$ These guidelines are widely publicized on the changeover day during the trainee doctor's induction program. Finally, since 2012, a diabetes-specific interactive 1-hour educational program for trainee doctors devised by this hospital was implemented during the changeover period, which takes them through practical and problemsolving case scenarios related to inpatient glycemic management, in particular prevention of hypoglycemia and hospital-acquired diabetic ketoacidosis. ${ }^{16}$ Attendance was mandatory, and informal feedback from trainee doctors about the educational program was extremely positive.

There are several limitations in this study. It could be argued that trainee doctors have very little impact on glycemic control in inpatients with diabetes. In NHS hospitals, trainee doctors are often the first port of call for managing glycemic issues in inpatients both in and out of hours, who in turn may or may not call the inpatient diabetes team wherever available. Therefore, trainee doctors' impact on glycemic control in inpatients with diabetes cannot be understated. However, it is acknowledged that in this study, a number of other factors that influence inpatient glycemic control, such as individual patient characteristics, medication errors, and the knowledge and confidence levels of individual trainee doctors, were not accounted for. Nevertheless, such factors are unlikely to have been 
significantly different over the 3-year period. A further limitation was the unavailability of hospital-wide electronic CBG data prior to 2012 to determine whether changeover impacted on inpatient glycemic control prior to this period. Another limitation was the dependence on patient administration data to identify those with diabetes, as it is well recognized that coded data in hospital data management systems can be inaccurate, though this has significantly improved over the years. ${ }^{17}$ Finally, the most important limitation is that this is a single-hospital study, and so the results may not be applicable to other English hospitals. Nevertheless, the finding of this study is similar to the finding in the single-hospital study from the United States. $^{8}$

The finding that glycemic control in inpatients with diabetes did not worsen in the 4 weeks following changeover of trainee doctors compared to the 4 weeks before changeover each year suggests that appropriate forethought and planning by the deanery foundation school and the inpatient diabetes team has prevented the anticipated deterioration of glycemic control during the August changeover of trainee doctors in this English hospital.

Disclosures: R.R. and G.R. conceived and designed the study. R.R. collected data and drafted the manuscript. R.R., D.J., and G.R. analyzed and interpreted the data. D.J. provided statistical input for analysis of the data. R.R., D.J., and G.R. critically revised the manuscript for intellectual content. All authors have approved the final version. The authors report no conflicts of interest.

\section{References}

1. Innes E. Black Wednesday: today junior doctors will start work-and cause A\&E death rates to increase by SIX per cent 2013. Daily Mail website. Available at: http://www.dailymail.co.uk/health/article-
2385931/Black-Wednesday-Today-junior-doctors-start-work-causingA-E-death-rates-6.html. Published August 7, 2013. Accessed October 7, 2014.

2. Jen MH, Bottle A, Majeed A, Bell D, Aylin P. Early in-hospital mortality following trainee doctors' first day at work. PLoS One. 2009;4(9): e7103.

3. Aylin P, Majeed FA. The killing season-fact or fiction? BMJ. 1994; 309(6970):1690.

4. Young JQ, Ranji SR, Wachter RM, Lee CM, Niehaus B, Auerbach AD. "July effect": impact of the academic year-end changeover on patient outcomes: a systematic review. Ann Intern Med. 2011;155(5): 309-315.

5. Phillips DP, Barker GE. A July spike in fatal medication errors: a possible effect of new medical residents. J Gen Intern Med. 2010;25(8): 774-779.

6. Inaba K, Recinos G, Teixeira PG, et al. Complications and death at the start of the new academic year: is there a July phenomenon? J Trauma. 2010;68(1):19-22.

7. Borenstein SH, Choi M, Gerstle JT, Langer JC. Errors and adverse outcomes on a surgical service: what is the role of residents? J Surg Res. 2004;122(2):162-166.

8. Nicolas K, Raroque S, Rowland DY, Chaiban JT. Is There a "July Effect” for inpatient glycemic control? Endocr Pract. 2014;20(19): 919-924.

9. George JT, Warriner D, McGrane DJ, et al.; TOPDOC Diabetes Study Team. Lack of confidence among trainee doctors in the management of diabetes: the Trainees Own Perception of Delivery of Care (TOPDOC) Diabetes Study. OJM. 2011;104(9):761-766.

10. Goldberg PA, Bozzo JE, Thomas PG, et al. "Glucometrics"—assessing the quality of inpatient glucose management. Diabetes Technol Ther. 2006;8(5):560-569.

11. Newbold P, Carlson WL, Thorne B. Statistics for Business and Economics. 5th ed. Upper Saddle River, NJ: Prentice Hall; 2002.

12. Louviere JJ, Hensher AD, Swait DJ. Stated choice methods. New York, NY: Cambridge University Press; 2000.

13. Health Education East of England. Preparing for professional practice. Available at: https://heeoe.hee.nhs.uk/foundation_faq. Accessed October 07, 2015.

14. Department of Health. Lives will be saved as junior doctors shadow new role 2012. Available at: https:/www.gov.uk/government/news/ lives-will-be-saved-as-junior-doctors-shadow-new-role. Accessed October 29, 2014.

15. Association of British Clinical Diabetologists. Joint British Diabetes Societies for Inpatient Care. Available at: http://www.diabetologistsabcd.org.uk/JBDS/JBDS.htm. Accessed October 8, 2014.

16. Taylor CG, Morris C, Rayman G. An interactive 1-h educational programme for junior doctors, increases their confidence and improves inpatient diabetes care. Diabet Med. 2012;29(12):1574-1578.

17. Burns EM, Rigby E, Mamidanna R, et al. Systematic review of discharge coding accuracy. J Public Health (Oxf). 2012;34(1):138-148. 